\title{
Critical Role of the Carbohydrate Side Chains of Collagen in Platelet Aggregation
}

\author{
Carolyn McI. Chesney, Elvin Harper, and Robert W. Colman \\ From the Hematology and Developmental Biology Units of the Department of \\ Medicine, Massachusetts General Hospital and the Department of Medicine, \\ Harvard Medical School, Boston, Massachusetts 02114
}

\begin{abstract}
A в S T RAC T The reaction between human platelet membrane glucosyl transferase and collagen has recently been proposed as the mechanism for plateletcollagen adhesion. Collagen contains glucosyl-galactose and galactose side chains linked through the galactose to hydroxylysine. Oxidation of the 6-hydroxymethyl position of the galactosyl residue to aldehydes with galactose oxidase completely abolishes platelet aggregation. This enzymatic modification of collagen can be fully reversed by reduction of the aldehydes formed by $\mathrm{NaBH}_{4}$ with complete restoration of platelet aggregating ability. Limited digestion with bacterial collagenase abolishes the ability of collagen to aggregate platelets. Removal of the $N$-terminal telopeptides from collagen with trypsin does not affect platelet aggregation. Tertiary structure of soluble collagen is essential for platelet aggregation. Normal collagen is less effective than lathyritic collagen, which contains only a small number of cross-links. The decreased number of aldehyde groups in the lathyritic collagen are not responsible for the increase in aggregating ability, since reduction with $\mathrm{NaBH}_{4}$ does not alter platelet aggregation. These results suggest that integrity and accessibility of the galactose receptor site may be crucial for the formation of a ternary collagenenzyme-platelet membrane complex which must precede platelet aggregation.
\end{abstract}

\section{INTRODUCTION}

The initial event in hemostasis has been postulated to be the adherence of platelets to connective tissue. This reaction is rapidly followed by aggregation of platelets with release of certain intracellular substances and eventual irreversible aggregation. A number of observations have been made concerning the nature of the

Received for publication 27 March 1972 and in revised form 27 June 1972. initial interaction between platelets and collagen. AlMondhiry and Spaet (1) have suggested that free or intact sulfhydryl groups in the platelet are necessary. Wilner, Nossel, and LeRoy (2) showed that deamination or blockage of free amino groups of collagen resulted in greater than $90 \%$ reduction in platelet aggregating activity. They concluded that the epsilon amino groups of the collagen molecule were critical for platelet aggregating activity, whereas the carboxyl groups are of little importance. Studies by Jamieson, Urban, and Barber $(3,4)$ suggest that a platelet membranecollagen complex is formed through the mediation of a membrane bound glucosyl transferase and that this is the molecular basis of platelet adhesion to collagen.

The purpose of this investigation is to attempt to quantify the response of platelets to collagen and to further elucidate the structural requirements for collagen-platelet interaction. The results suggest that multiple sites involving carboxyhydrate side chains may be necessary for platelet aggregation by collagen, and that the tertiary structure and degree of cross-linking may control the accessibility to these sites.

\section{METHODS}

\section{Platelet preparation and aggregometry}

Platelet-rich plasma (PRP).' Human blood from normal volunteers was collected into an anticoagulant solution (1 part $3.8 \%$ sodium citrate to nine parts whole blood) and centrifuged at $23^{\circ} \mathrm{C}$ for $10 \mathrm{~min}$ at $50 \mathrm{~g}$. Supernatant PRP was then removed by aspiration and used for the studies. Whole blood and plasma were exposed only to plastic surfaces. The platelet count varied from 200,000 to 350,000 per $\mu l$ during these studies.

Platelet-poor plasma (PPP). Blood was collected as PRP above and centrifuged at $2500 \mathrm{~g}$ for $10 \mathrm{~min}$. The platelet count was less than 40,000 platelets per $\mu 1$.

${ }^{1}$ Abbreviations used in this paper: PPP, platelet-poor plasma; PRP, platelet-rich plasma. 

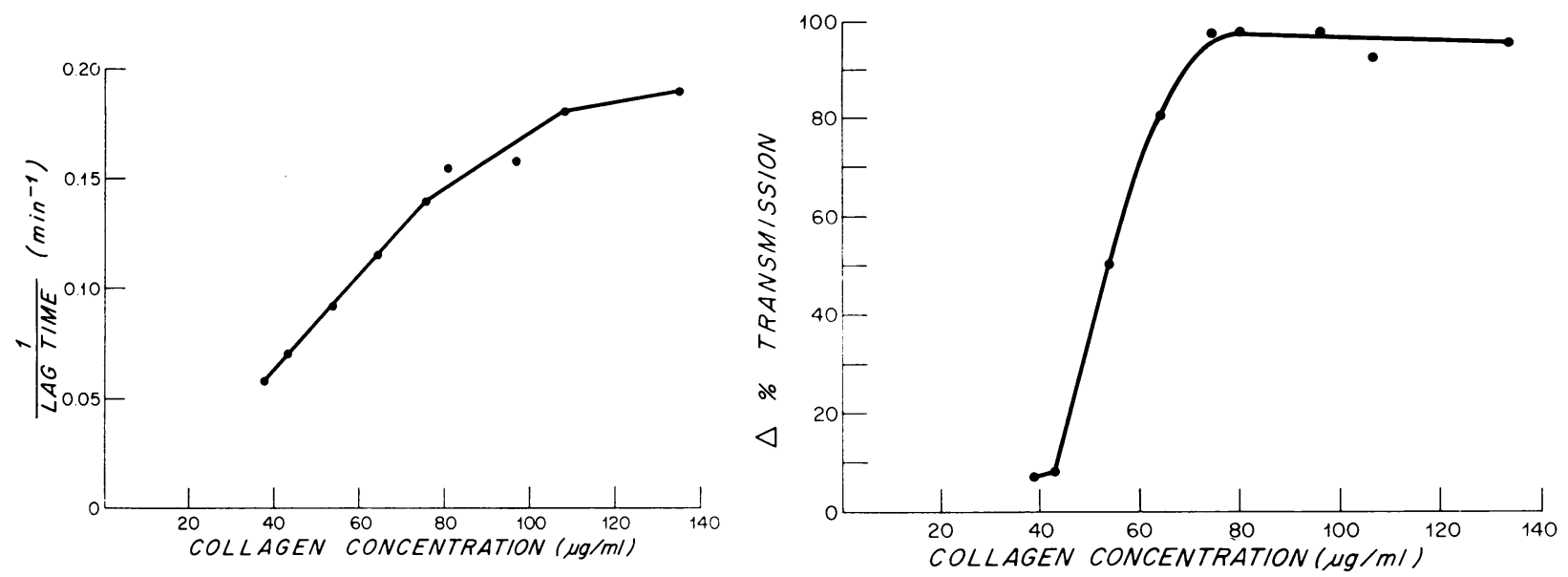

FIgURE 1 Standardization of response of platelets to varying collagen concentrations. Platelet aggregation was performed (as in Methods) with varying concentrations of guinea pig collagen. The reciprocal of the lag time $(A)$ and the amplitude expressed as difference in per cent transmission of light $(B)$ are plotted as a function of collagen concentration.

Platelet aggregometry. Platelet aggregation was carried out in a Chrono-log platelet aggregometer according to the method of Born (5). $\frac{1}{2} \mathrm{ml} \mathrm{PRP}$ was pipeted into a siliconized glass tube, diameter $8 \mathrm{~mm}$, and was stirred at a constant speed of $1100 \mathrm{rpm}$ at $37^{\circ} \mathrm{C}$. By means of a light source and a photoelectric cell, the aggregometer detects changes in the transmission of light of the PRP as aggregation occurs. The aggregometer was set so that the per cent of transmittance of PRP was recorded as 0 and that of PPP 100. The collagen preparation in $0.4 \mathrm{M} \mathrm{NaCl} \mathrm{pH}$ 6.5 was added in volumes of no more than $25 \mu \mathrm{l}$ in a final volume of $500 \mu \mathrm{l}$ after standardization for each new sample of PRP, except for the galactose oxidase treated collagen in which $100 \mu \mathrm{l}$ was used. The changes in per cent transmission were continuously recorded as a function of time by a Heath Servo-Recorder Model EL-20B (Heath Co. Benton Harbor, Mich.). The aggregation was followed for a total of $10 \mathrm{~min}$ and the difference between zero transmittance and maximum transmittance was tabulated. This change was defined as the amplitude of the response. The lag time was determined after a baseline was established at zero transmission with the PRP. The aggregating agent was added and the event marked on the recording paper. Platelets characteristically undergo a swelling phase, reflected by a decrease in transmission of light. The time from the addition of the aggregating agent to the beginning of increase in light transmission is defined as the lag time.

\section{Enzymes}

Bacterial collagenase was purified by the method of Harper and Kang (6). This enzyme has been shown to be free of nonspecific proteolytic activity as measured against denatured hemoglobin and casein. However, the specific activity of the enzyme varied from preparation to preparation, so each single experiment was carried out on one enzyme preparation.

Galactose oxidase (dactylium dendroides) was obtained from Sigma Chemical Co., St. Louis, Mo. Trypsin $(2 \times$ crystallized) was a product of Worthington Biochemical Corp., Freehold, N. J. Tadpole collagenase was prepared from tadpole tail fins by the procedure of Harper and Gross (7).

\section{Collagen preparations}

Acid-scluble guinca pig skin collagen was prepared by the method of Gross (8). This preparation was used for all studies unless otherwise specified. At $37^{\circ} \mathrm{C}$ no fibrils were detected by the method of Gross and Kirk (9) at a concentration range of $0.13-0.525 \mathrm{mg} / \mathrm{ml}$ in $0.4 \mathrm{M} \mathrm{NaCl}$ or citrated plasma during a period of $30 \mathrm{~min}$ with constant magnetic stirring. The platelet aggregating activity of the collagen varied with different preparations of the collagen. For this reason, each experiment was performed with collagen of a single lot.

Lathyritic guinea pig skin collagon was isolated from guinea pigs weighing $200 \mathrm{~g}$ which were given intraperitoneally $0.7 \mathrm{mg} / 100$ body wt beta aminopropionitrile daily for $2 \mathrm{wk}$. The skin of the guinea pigs was extracted with 0.45 if $\mathrm{NaCl}$ as described by Gross and Kirk (9).

Calf skin collagcn (acid soluble) prepared by the method of Gallop and Seifter (10) was purchased from Sigma Chemical Co.

\section{Chemicals}

Other chemicals were reagent grade and were obtained from the following suppliers: Tris and cysteine $\mathrm{HCl}$ from Sigma Chemical Co., sodium borohydride from Alfa Inorganic Inc. (Ventron Corp.), Beverly, Mass., and hydroxyproline, A grade, from Calbiochem. Los Angeles, Calif.

\section{Enzymatic treatment of collagen}

Bacterial collagenase digestion was performed at $0^{\circ} \mathrm{C}$ with weight ratios varying from $1: 20$ to $1: 50$ parts of bacterial collagenase to collagen. In a typical experiment $50 \mu \mathrm{l}$ of a collagenase solution in $0.05 \mathrm{M}$ Tris containing $0.005 \mathrm{M} \mathrm{CaCl}_{2} \mathrm{pH} 7.4$ was added to $500 \mu \mathrm{l}$ of collagen in $0.4 \mathrm{M} \mathrm{NaCl}$. Portions were taken at given time intervals and assayed for ability to aggregate platelets. Separate portions for disc electrophoresis analysis were removed and the reaction was terminated by addition of a volume of $50 \%$ acetic acid, which was sufficient to lower the $\mathrm{pH}$ to 4.2 . No further enzymatic cleavage took place as monitored by polyacrylamide disc electrophoresis at varying times after the reaction was terminated. 


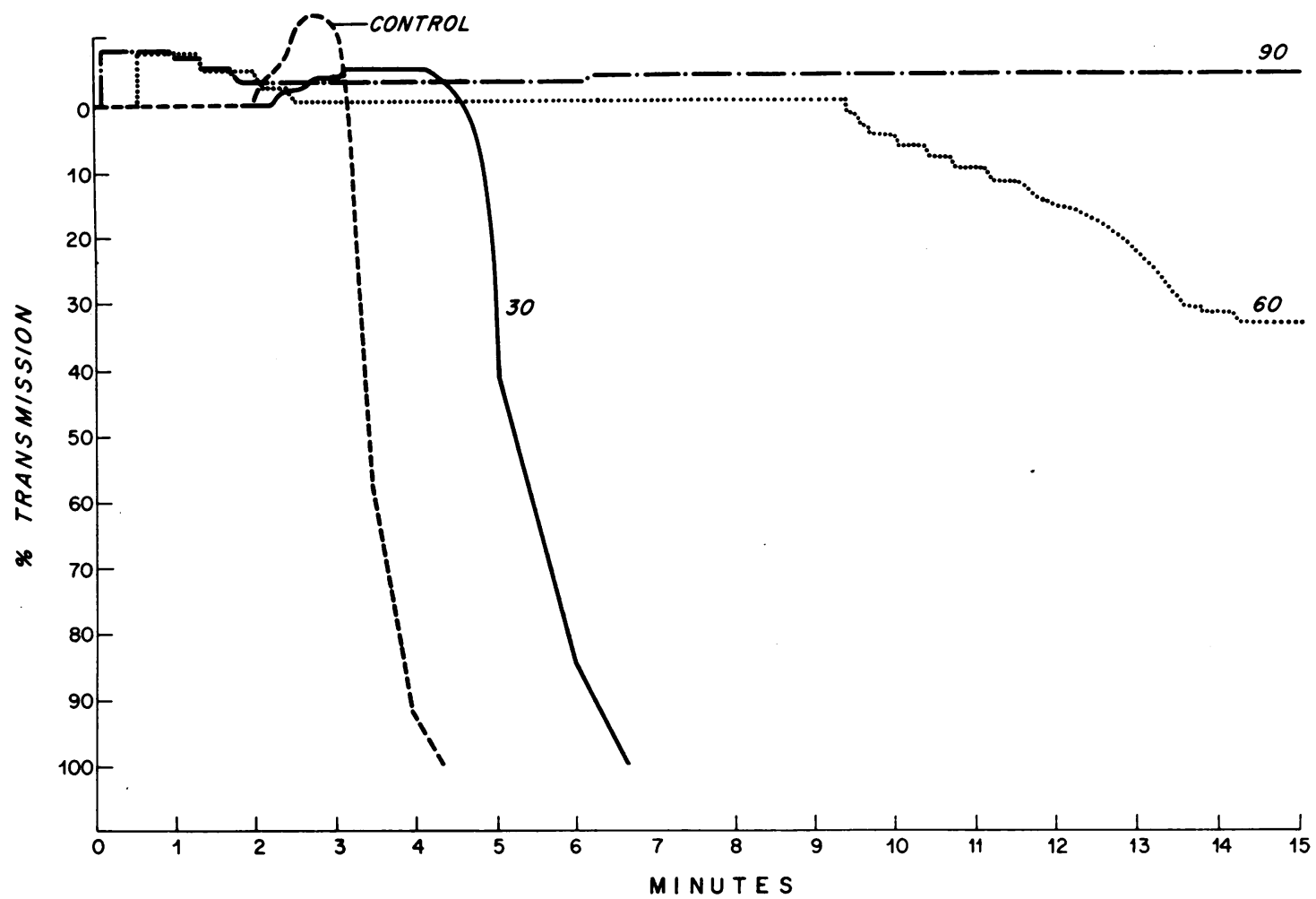

FIGURE 2 Effect of limited digestion of bacterial collagenase. Bacterial collagenase $(5.0 \mu \mathrm{g})$ was added to $2.2 \mathrm{mg}$ guinea pig collagen in a final volume of $1 \mathrm{ml}$. Enzymatic digestion was carried out at $0^{\circ} \mathrm{C}$. Portions of $20 \mu \mathrm{l}$ were taken at $0,30,60$, and $90 \mathrm{~min}$, respectively, and added to $0.5 \mathrm{ml} \mathrm{PRP}$ in the platelet aggregometer. The curves are exact tracings of those recorded.

Tadpole collagenase digestion was performed by adding $100 \mu \mathrm{g}$ of the enzyme to $4 \mathrm{mg}$ of soluble guinea pig collagen in a final volume of $1.2 \mathrm{ml}$ of $0.05 \mathrm{M}$ Tris $\mathrm{pH} 7.4$ containing $0.005 \mathrm{M} \mathrm{CaCl}_{2}$ and $0.04 \mathrm{M} \mathrm{NaCl}$ at $27^{\circ} \mathrm{C}$. Upon completion of the reaction as measured by viscosity, the reaction products were assayed for platelet aggregation activity. In previous studies this procedure was found to result in a cleavage of the collagen molecule, giving rise to two reaction products representing, respectively, the $C$-terminal onequarter and the $N$-terminal three-quarters of the collagen molecule (11).

Trypsin digestion was initiated by adding $40 \mu \mathrm{g}$ of freshly prepared enzyme in $0.05 \mathrm{~m}$ Tris $\mathrm{pH} 7.4$ with $0.005 \mathrm{M} \mathrm{CaCl}_{2}$ and $0.4 \mathrm{M} \mathrm{NaCl}$ to $4 \mathrm{mg}$ of soluble guinea pig skin collagen in the same buffer. The final volume of the incubation mixture was $1.5 \mathrm{ml}$. The mixture was incubated at $24^{\circ} \mathrm{C}$ for $24 \mathrm{hr}$, terminated by cooling to $0^{\circ} \mathrm{C}$ and assayed for its ability to aggregate platelets. Under these conditions, trypsin is known to cleave telopeptides from collagen $(12,13)$.

Galactose oxidase $(0.5 \mathrm{mg})$ in $0.03 \mathrm{M}$ Tris, $\mathrm{pH} 7.0$, was added to $4 \mathrm{mg}$ of soluble guinea pig skin collagen in the same buffer in a total volume of $1.2 \mathrm{ml}$. The mixture was incubated for $16 \mathrm{hr}$ at $24^{\circ} \mathrm{C}$. A control sample of the same collagen was incubated under identical conditions. Under these conditions $(14,15)$ the enzyme oxidizes the 6-hydroxyl group of galactose to the aldehyde whether the sugar is free or combined in glycosidic linkage.

\section{Chemical and physical modifications of collagen}

Thermal denaturation (16) was effected by incubating a stock solution of soluble guinea pig skin collagen (2.1 $\mathrm{mg} / \mathrm{ml}$ ) in $0.4 \mathrm{M} \mathrm{NaCl}$ for $10 \mathrm{~min}$ at $50^{\circ} \mathrm{C}$ and terminating the experiment by adjusting this temperature to $0^{\circ} \mathrm{C}$.

Sodium borohydride reduction was performed using solid sodium borohydride $(2.0 \mathrm{mg})$ added with stirring to 6.4 $\mathrm{mg}$ of soluble guinea pig skin collagen in a total volume of $3.2 \mathrm{ml}$ of $0.05 \mathrm{M}$ Tris, $\mathrm{pH} 8.9$, containing $0.4 \mathrm{M} \mathrm{NaCl}$. The reaction mixture was stirred for $1 \mathrm{hr}$ with additions of $0.1 \mathrm{M} \mathrm{NaOH}$ as needed to maintain the $\mathrm{pH}$. The mixture was then stored at $0^{\circ} \mathrm{C}$ for $3 \mathrm{hr}$. The reaction was terminated by the addition of a volume of $50 \%$ acetic acid sufficient to lower the $\mathrm{pH}$ to 4.2 . The resulting reaction products were dialyzed vs. $0.4 \mathrm{M} \mathrm{NaCl}$ at $4^{\circ} \mathrm{C}$ overnight. This procedure is known to reduce aldehydes in collagen to alcoholic groups (17).

\section{Analytic procedures}

Polyacrylamide disc electrophoresis was used to examine collagen reaction products $(80-160 \mu \mathrm{g})$ at $\mathrm{pH} 3.8$ using the method of Nagai, Gross, and Piez (18).

Measurement of hydroxy'proline in collagen was performed by the method of Bergman and Loxley (19). The assumption is made that $14 \%$ of the weight of collagen is com- 


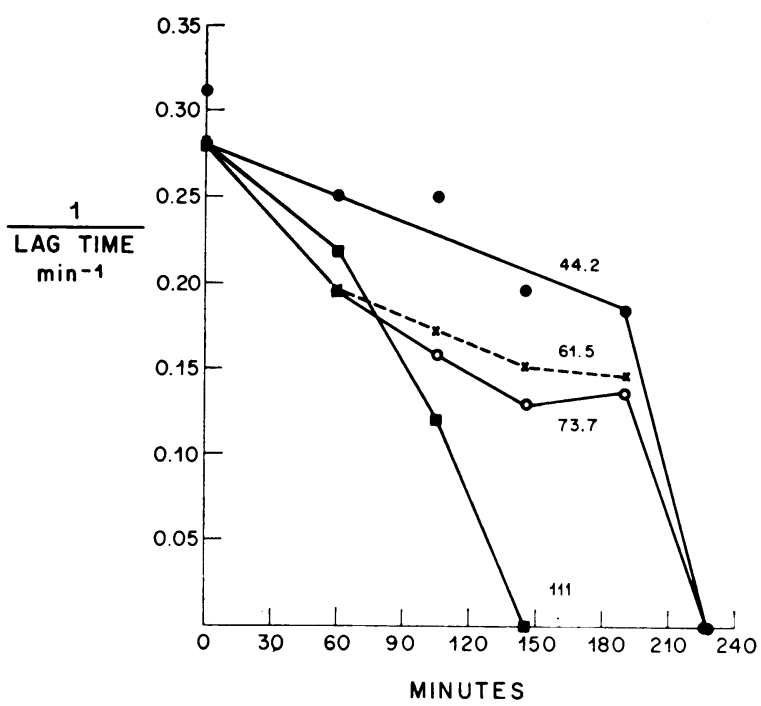

FIGURE 3 Dependence of the lag time on degree of digestion by collagenase. Collagen $(2.2 \mathrm{mg} / \mathrm{ml})$ was digested at $0^{\circ} \mathrm{C}$ with the following collagenase concentrations: 44.4, $61.5,73.7$, and $111 \mu \mathrm{g} / \mathrm{ml}$. 50- $5 \mathrm{l}$ portions of each sample were taken at $0,60,105,145,190$, and $225 \mathrm{~min}$, respectively, and were added to $0.5 \mathrm{ml} \mathrm{PRP}$ in the aggregometer. The reciprocal of the lag time of each sample is plotted as a function of time for each collagenase concentration.

posed of hydroxyproline, and collagen concentration (micrograms per milliliter) is calculated by multiplying the hydroxyproline values by 7.1 .

\section{RESULTS}

Effect of collagen concentration on platelet aggregation. The concentration of collagen used in aggregating platelets affected both the lag time and the amplitude. As the concentration of collagen was increased, there was a progressive shortening of the lag time until a plateau was reached. Over a range of $38-76 \mu \mathrm{g} / \mathrm{ml}$, the reciprocal of the lag time was found to be linearly proportional to the collagen concentration (Fig. 1A). The change in amplitude when plotted against collagen concentration yielded a much steeper slope (Fig. 1B) and the range of concentrations which gave intermediate values was more limited than the reciprocal lag time. As is seen in Fig. 2, the lag time seems to be affected before the amplitude when collagen is modified. Thus. the reciprocal lag time has been used as one index of the functional activity of collagen on platelets in this study.

Effect of proteolytic digestion on platelet aggregation by collagen. Soluble guinea pig skin collagen was subjected to limited digestion by bacterial collagenase and the digestion products tested for their ability to aggregate platelets (Fig. 2). After incubation for $30 \mathrm{~min}$, an increase in the lag time was noted and by $60 \mathrm{~min}$ the lag time had tripled in duration. No change in amplitude was noted at $30 \mathrm{~min}$ but at $60 \mathrm{~min}$ the response was only one-third of that of the control. Total loss of platelet aggregating ability of the collagen occurred at $90 \mathrm{~min}$ of digestion. Similar changes were noted when calf skin collagen was digested with collagenase under the same conditions.

Digestion of the collagen by bacterial collagenase was studied both as a function of enzyme concentration at given times and as a function of time for a known amount of enzyme. At the concentrations studied there was progressive loss over time of the aggregating activity of the collagen as measured by a decrease in the reciprocal lag time (Fig. 3). The reaction appears to proceed in two distinct phases at lower collagenase concentrations $(44.2-73.7 \mu \mathrm{g} / \mathrm{ml}$. A gradual loss was followed by a more rapid decrease until no platelet aggregating ability was observed.

The digestion was followed by analysis of the reaction products using disc gel electrophoresis (Fig. 4). The control sample displays the characteristic forms of collagen. At the top of the gel is the gamma (three chain) collagen with a molecular weight 300,000 . The next band (beta) represents a molecular weight of 200.000 . The third band (alpha) is the 100,000 monomer. Products running faster than the alpha band are assumed to have molecular weights of less than 100,000 . Since no nonspecific proteases are present, this assumption regarding molecular weight is probably valid. At $111 \mu \mathrm{g} / \mathrm{ml}$ of collagenase. prolongation of the lag time

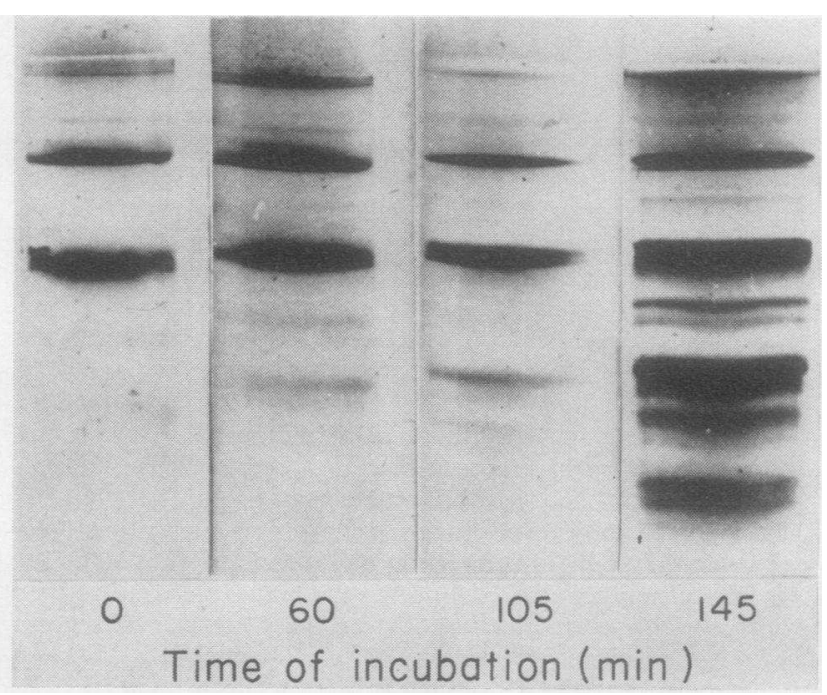

FIGURE 4 Electrophoretic changes in collagen during digestion by collagenase. Polyacrylamide disc electrophoresis of the reaction products of collagenase $(111 \mu \mathrm{g} / \mathrm{ml})$ digestion of collagen $(2.2 \mathrm{mg} / \mathrm{ml})$ at the indicated incubation times. The reaction was stopped at the specified time by the addition of 1 vol of $50 \%$ acetic acid for each 10 vol of the portion of the digest. A $25 \mu 1$ portion was used for each gel. 


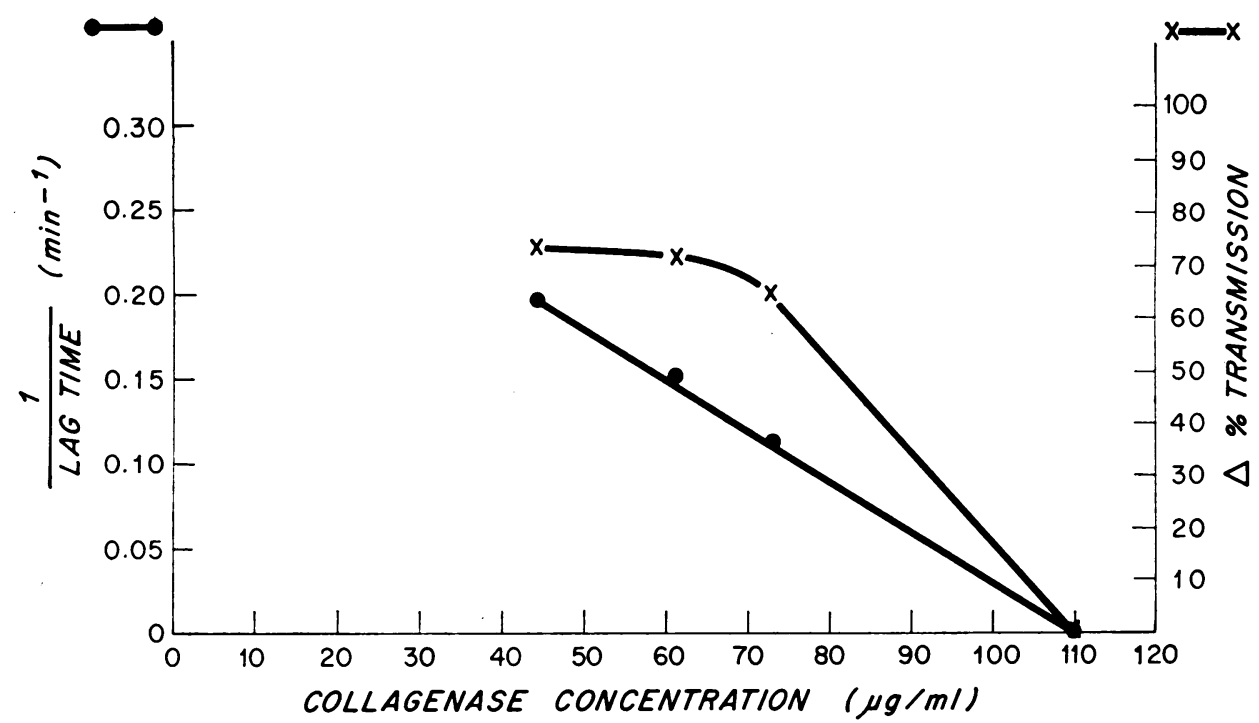

Figure 5 Dependence of lag time and amplitude on concentration of collagen use during digestion. Collagen was digested with collagenase and portions of the digest were used to aggregate platelets, as in Fig. 3. The reciprocal of the lag time is shown as a function of the collagenase concentration at a single time, $145 \mathrm{~min}$ as is the amplitude of the response of platelets to collagen.

seemed to be associated with the appearance of several peptide fragments of molecular weight less than 100,000 (60 and $105 \mathrm{~min}$ ). Total loss of activity, on the other hand, was associated with much more extensive digestion $(145 \mathrm{~min})$ and with the appearance of multiple small fragments. During the entire digestion, there was no major alteration in the three chains of collagen detectible by electrophoresis (20).

If the time were held constant and the enzyme concentration varied (Fig. 5), there was loss of platelet aggregating activity proportional to the concentration of bacterial collagenase at all time points measured when the reciprocal lag time is measured. The amplitude appears less sensitive for early times of digestion. Polyacrylamide disc gel electrophoresis studies (not shown) of the collagen digested for $145 \mathrm{~min}$ showed that the extent of formation of small fragments was proportional to the enzyme concentration and closely paralleled the aggregation changes noted in Fig. 5. The disc electrophoresis patterns were similar to those of Fig. 4.

To test whether the effect of collagenase was due specifically to its enzymatic action, the enzyme was pretreated with a known inhibitor, cysteine, which is thought to cover a metal-containing site necessary for substrate binding (21). After exposure of collagenase to $0.02 \mathrm{~m}$ cysteine, $\mathrm{pH} 7.0$ for $45 \mathrm{~min}$, conditions known to inhibit the enzyme (21), inhibition of platelet aggregation by collagenase is prevented and the platelets aggregate normally when exposed to collagen. Moreover, incubation of platelets themselves with native collagenase in no way alters their normal response to added collagen.

Two possible explanations for the loss of platelet aggregation activity of collagen as it is digested by collagenase should be considered. The decrease in activity may be consequent to limited proteolytic alteration of one or more of the collagen chains. Alternatively, the smaller digestion products may interfere with interaction of collagen and platelets. To test the latter hypothesis, collagen $(2.2 \mathrm{mg} / \mathrm{ml})$ was digested with collagenase $(50 \mu \mathrm{g} / \mathrm{ml})$ for $85 \mathrm{~min}$. The aggregating ability of collagen was demonstrated to be absent by $30 \mathrm{~min}$ of digestion. The digestion products $\left(\begin{array}{lll}20 \mu 1\end{array}\right)$ were then added to $0.5 \mathrm{ml} \mathrm{PRP}$ and incubated at $23^{\circ}$ for $10 \mathrm{~min}$. When $44 \mu \mathrm{g}$ collagen in $20 \mu \mathrm{l}$ was subsequently added to the PRP, no change in aggregation of the platelets was found when compared with the control. Thus, the changes must be due to subtle alterations of the collagen chains which do not affect their mobility on disc electrophoresis.

Digestion with tadpole collagenase which cleaves each of the three chains at one point resulted in complete loss of activity. In contrast, trypsin, which cleaves only the telopeptides, did not alter the activity of collagen on platelets.

Effect of secondary and tertiary structure of collagen on platelet aggregation. Since collagen could be modified only in limited fashion without impairing its activity, the effect of cross-linking on collagen reactivity was investigated. The platelet aggregating activity was 


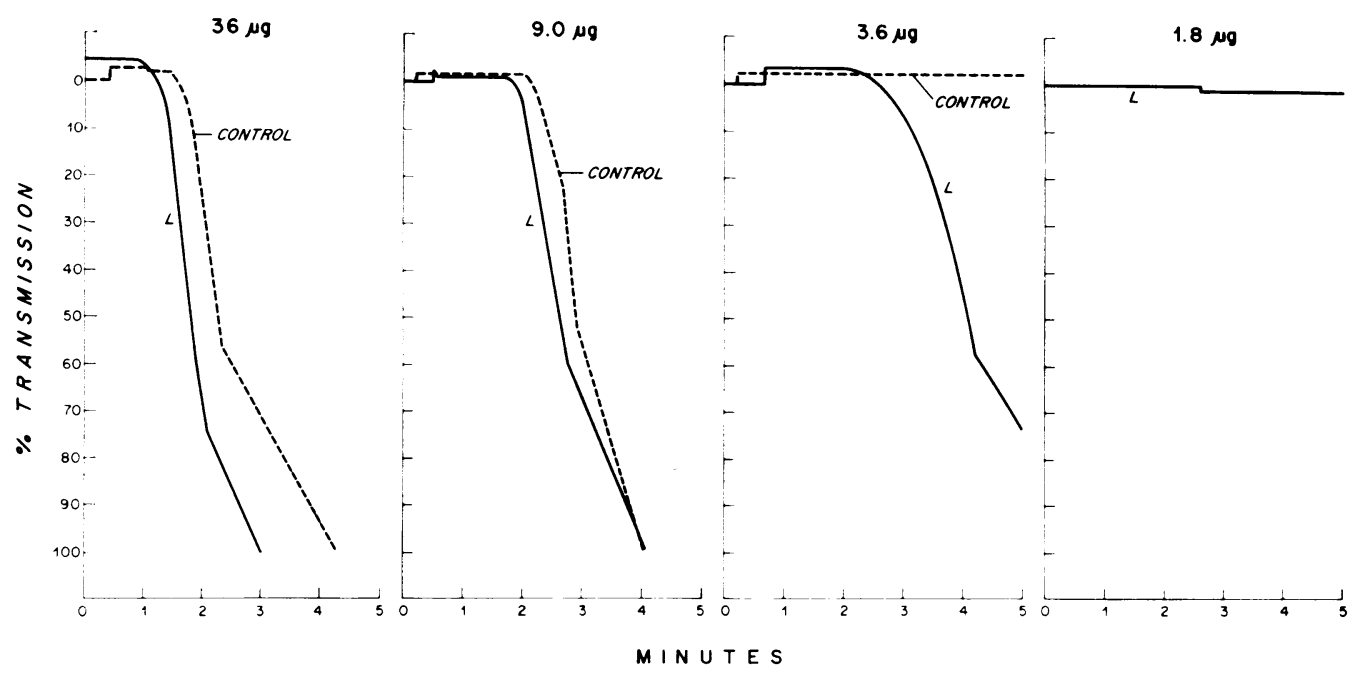

Figure 6 Aggregation experiments with normal and lathyritic (L) collagens at different concentrations. Collagen to give final concentrations of $36,9.0,3.6$, and $1.8 \mu \mathrm{g} / \mathrm{ml}$ of the respective collagens was added to $\mathrm{PRP}$ and aggregation was monitored. The graphs are actual tracings of the recorded experiments.

determined at low concentrations of soluble guinea pig skin collagen obtained from normal animals and from lathyritic collagen, which has fewer cross-links. The lathyritic collagen supported platelet aggregation more effectively than the normal collagen (Fig. 6). This increase in activity is particularly evident when $1 \mu 1$ containing $1.8 \mu \mathrm{g}$ collagen is added to $0.5 \mathrm{ml}$ of $\mathrm{PRP}$ to give a final concentration of $3.6 \mu \mathrm{g} / \mathrm{ml}$. This concentration showed no aggregation with normal collagen, while lathyritic collagen gave $70 \%$ of the maximum amplitude and showed an unchanged lag time. The amount of normal collagen needed to give an equivalent aggregation was 2.5 times the amount of lathyritic collagen. This experiment was repeated three times with similar results. The triple helical structure of collagen is thought to be essential for the effect of collagen on platelets, but previous experiments have employed low $\mathrm{pH}$ and long incubation time in producing thermal denaturation. Collagen exposed to a temperature of $50^{\circ}$ for $10 \mathrm{~min}$ at neutral $\mathrm{pH}$ failed to support platelet aggregation.

Effect of spccific functional groups of collagen on platelct aggregation. Jamieson has suggested a key role for the carbohydrate moiety of collagen in adhesion to platelets $(3,4)$. Exposure of soluble guinea pig skin collagen to galactose oxidase resulted in total obliteration of platelet aggregation (Fig. $7 B$ ). A sample of the same collagen incubated under the same conditions of $\mathrm{pH}$ and ionic strength showed normal aggregation (Fig. 7 control). The normal control collagen gave a full aggregation even at one-fourth of the concentration of the galactose oxidase-treated collagen. Despite the absence of demonstrable proteases or other hydrolytic enzymes in the galactose oxidase, it was of interest to ascertain whether the effect of this enzyme was due entirely to the oxidation of the 6-hydroxyl position of galactose to an aldehyde or to an irreversible conformational or other unrelated change in the molecule. Since the role of aldehyde groups in collagen, other than those involved in cross-linking, is unknown, the effect of reducing the aldehyde groups in native collagen to alcohol residues was first explored using $\mathrm{NaBH}_{4}$. This chemical modification did not alter the platelet aggregating ability of the collagen (Fig. 7A). Therefore, an attempt was made to reverse the galactose oxidase catalyzed modification of collagen. After obliteration of collagen activity by galactose oxidase, the collagen was then reduced with $\mathrm{NaBH}_{4}$. Complete restoration of the activity of collagen was obtained (Fig. $7 C$ ), indicating that the enzymatic modification was fully reversible.

As indicated previously, native collagen preparations varied in their ability to induce platelet aggregation (Fig. 1 vs. Fig. 6). Since the galactose oxidase experiment (Fig. 7 ) was performed with a collagen that required $44 \mu \mathrm{g} / \mathrm{ml}$ to give a full response, we were concerned that the same effect might not be evident with the most active collagen preparation. Therefore we repeated the experiment using a collagen which was fully effective at $11.6 \mu \mathrm{g} / \mathrm{ml}$ comparable to the most active collagen observed (Fig. 6). When this collagen was incubated under the conditions employed for reaction with galactose oxidase but omitting the enzyme, the sensitivity declined to $19.2 \mu \mathrm{g} / \mathrm{ml}$ for a full response, 
probably due to thermal denaturation or dilution. In contrast, $192 \mu \mathrm{g} / \mathrm{ml}$ of the same collagen treated with galactose oxidase showed no response, indicating at least a 10 -fold loss of activity.

\section{DISCUSSION}

All the experiments in the present investigation have been performed with soluble collagen. Suspensions of certain insoluble materials, such as kaolin and latex particles, are known to aggregate platelets (22). Despite the fact that insoluble collagen may interact selectively with platelets (2), in studying the functional properties of collagen it seemed preferable to avoid possible nonspecific effects of suspensions. Highly purified soluble collagen offered the possibility of identifying that portion of the collagen molecule which is essential to its interaction with platelets. The lag phase, which is dependent on both concentration and possibly the time to form microfibrils (23), was found to be useful in measuring collagen function.

Collagen is known to have at least two roles in primary hemostasis. This protein initiates adhesion of platelets to itself and to each other. This event requires no calcium and is probably mediated through the action of glucosyl transferase in the platelet membrane (3). In addition, collagen causes the irreversible aggregation of platelets with release of certain intracellular components such as nucleotides (24), antiheparin activity and serotonin (25). Platelet aggregation, which may be secondary to ADP, requires calcium (26).

Collagen contains glucosyl galactosyl hydroxylysine (2-0- $\alpha$-D-glucosyl-0- $\beta$-D-galactosyl hydroxylysine) (15). Studies by Jamieson et al. $(3,4)$ have suggested an enzymatic basis for platelet-collagen adhesion. Platelets are known to contain the enzyme glucosyl transferase, which catalyzes the transfer of glucose from uridine diphosphoglucose to incomplete heterosaccharide chains of collagen $(3,4)$. This hypothesis suggests that the structural integrity of the unsubstituted galactose residue would be essential, since galactose acts as the receptor for the enzymatically transferred glucose. In our study, oxidation of galactose residues by galactose oxidase, which removes two hydrogens from the 6 position and yields the corresponding aldehyde, completely abolished the ability of the collagen to aggregate platelets. That this specific oxidation is alone responsible is substantiated by the restoration of full aggregating activity to the collagen when the new aldehyde groups formed by galactose oxidase are reduced by $\mathrm{NaHB}_{4}$. Since the loss of only two hydrogen atoms from each galactose does not result in a significant alteration in charge or size of the galactosyl residue, a conformational change in the molecule or steric change in the site appears unlikely. The 6-hydroxyl position of galactose appears to

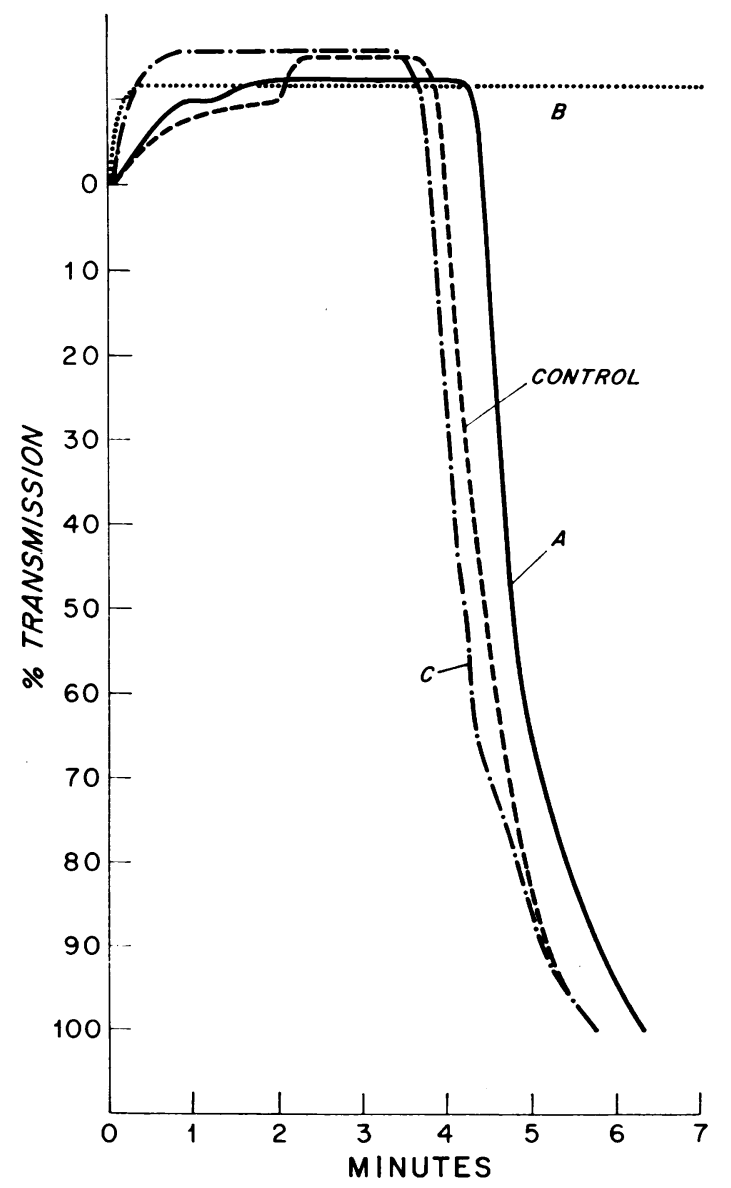

Figure 7 Effect of galactose oxidase and $\mathrm{NaBH}_{4}$ on the ability of collagen to aggregate platelets. (A) Soluble guinea pig collagen was treated with $\mathrm{NaBH}$, alone (see Methods). ( $B$ ) Soluble guinea pig collagen was treated with galactose oxidase alone (see Methods). ( $C$ ) Solub'e guinea pig collagen was treated sequentially first with galactose oxidase and then $\mathrm{NaBH}_{4}$. Control: a portion of the identical sample of collagen used in $A-C$ was carried through the entire procedure but omitting the galactose oxidase and $\mathrm{NaBH}_{4}$ treatment. In all cases $(A, B, C$, and control), $44 \mu \mathrm{g}$ collagen was then added to $0.5 \mathrm{ml} \mathrm{PRP}$ and aggregation was recorded.

be crucial for the activity of the collagen. It is likely, though not yet proven, that this hydroxyl group plays an essential role in directing the attachment of glucose to galactose by the transferase.

Previous workers (2) have demonstrated that extensive digestion of collagen with collagenase at $37^{\circ}$ for $48 \mathrm{hr}$ completely abolished its ability to aggregate platelets under conditions known to convert the collagen molecule to small peptides of an average molecular weight of 500 (27). In contrast, the limited digestion in this study $\left(0^{\circ}\right.$ for no more than $\left.4 \mathrm{hr}\right)$ of guinea pig collagen with bacterial collagenase liberated small amounts of peptide material without grossly altering 
the size of the collagen chains. A small molecular change is therefore enough to inhibit the ability of collagen to aggregate platelets. The fact that the gradual loss of platelet aggregating activity was observed during the limited digestion by collagenase might be explained by two distinct hypotheses. Multiple sites may be involved, or a single critical residue exists whose destruction causes loss of activity. The latter would require a mixture of fully active collagen molecules with completely inactive entities, which seems less likely.

When collagen is cleaved by collagenase, the possibility exists that the reaction products might be inhibitory. However, when these products were added to collagen in the aggregating system, there was no alteration in the normal effect of collagen. Similarly, collagenase had no effect on platelets themselves. The reaction products failed to aggregate platelets, although all the receptors are present in the mixture. Several hypotheses might explain this result. There may be a minimum size requirement for the aggregation of platelets by collagen. Alternatively, the fragments may be more soluble and more susceptible to thermal denaturation, as evidenced by their lower melting point (11).

Previous work by Wilner et al. (2) showed that pepsin digestion fails to alter the ability of insoluble collagen to aggregate platelets. Like pepsin, trypsin is also known to cleave the telopeptides from the collagen molecule. The failure of trypsin in our study to alter collagen-induced platelet aggregation is consistent with the critical importance of galactose residues, since no galactose has been found in this region of the molecule.

The importance of maintaining the tertiary structure of the molecule is shown by complete obliteration of platelet aggregating activity by thermal denaturation of the molecule. Wilner et al. (2) were able to destroy the ability of collagen to aggregate platelets by ther-

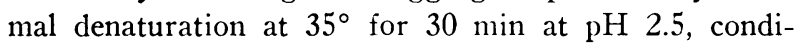
tions entirely different from those used in this study $\left(50^{\circ}, 10 \mathrm{~min}, \mathrm{pH} 7.0\right)$. The collagen molecule consists of three polypeptide chains that are coiled about a common axis to form a triple helix (28). These chains are held together by characteristic cross-links (29). The question arises as to what role the cross-links play in platelet interaction. In this study, we compared studies of platelet aggregating activities at low collagen concentrations using guinea pig collagen from normal and lathyritic animals. Lathyritic collagen, which has fewer cross-links and therefore is analogous to young collagen, supported platelet aggregation better than did normal collagen. More extensive cross-linking may mean that fewer galactose residues are sterically ac- cessible to the glucosyl transferase enzyme of the platelet membrane.

It is not known whether aldehyde groups have any function in collagen other than in forming cross-links. Reduction with $\mathrm{NaBH}_{4}$ did not alter platelet aggregation. suggesting that the aldehyde groups play a negligible role in the action of collagen in aggregating platelets.

The crucial role of the galactose residues suggests an explanation for the essential role of epsilon amino groups documented by Wilner et al. (2). The proximity of the amino group of hydroxylysine to the glucose-galactosyl linkage suggests that the charged ammonium ion may play a role in the substrate specificity of glucosyl transferase. Blockage of the epsilonamino groups inhibits kidney glucosyl transferase which catalyzes the transfer of glucose to the galactose receptor of the collagen $(30)$. It is not clear whether this modification produces a steric effect or merely a change in charge. Since the modification of amino groups inhibits the interaction of collagen with platelets (2), it appears that the platelet enzyme may have the same specificity as the kidney transferase.

This study provides direct evidence for the essential role of galactose in platelet aggregation probably by serving as the receptor site for platelet glucosyl transferase. It is tempting to hypothesize that the loss of aggregating activity of collagen during very limited proteolytic digestion represents loss of critical receptor sites from the triple helix of native collagen. Direct proof of this suggestion will require isolation of the receptor sites on the large peptides formed during the collagenase digestion. Such studies are presently underway in our laboratories.

\section{ACKNOWLEDGMENTS}

This work was partially supported by grants from the $\mathrm{Na}$ tional Institutes of Health (Nos. HE-11519 and AM-15367). Dr. Harper and Dr. Colman are the recipients of U. S. Public Health Service Career Development Awards (Nos. AM-34222 and HE-48,075, respectively). Dr. Chesney is the recipient of a Postdoctoral Fellowship (HE-48190).

\section{REFERENCES}

1. Al-Mondhiry, H., and T. H. Spaet. 1970. Inhibition of platelet adhesion to collagen by sulfhydryl inhibitors. Proc. Soc. Exp. Biol. Med. 135: 878.

2. Wilner, G. D., H. L. Nossel, and E. C. Leroy. 1968. Aggregation of platelets by collagen. J. Clin. Invest. 47 : 2616.

3. Jamieson, G. A., C. L. Urban, and A. J. Barber. 1971. Enzymatic basis for platelet: collagen adhesion as the primary step in hemostasis. Nat. Nezv Biol. 234: 5.

4. Barber, A. J., and G. A. Jamieson. 1971. Platelet collagen adhesion characterization of collagen glucosyl transferase of plasma membranes of human blood platelets. Biochim. Biophys. Acta. 252: 533. 
5. Born, G. V. R. 1962. Aggregation of blood platelets by adenosine diphosphate and its reversal. Nature (Lond.). 194: 927.

6. Harper, E., and A. H. Kang. 1970. Studies on the specificity of bacterial collagenase. Biochem. Biophys. Res. Commun. 41 : 482.

7. Harper, E., and J. Gross. 1970. Separation of collagenase and peptidase activities of tadpole tissue in culture. Biochim. Biophys. Acta. 198: 286.

8. Gross, J. 1958. Studies on the formation of collagen. Properties and fractionation of neutral salt extracts of normal guinea pig connective tissue. J. Expt. Med. $107: 247$.

9. Gross, J., and D. Kirk. 1958. The heat precipitation of collagen from neutral salt solution: some rate-regulating factors. J. Biol. Chem. 233: 355.

10. Gallop, P. M., and S. Seifter. 1963. Preparation and properties of soluble collagens. Methods Enzymol. 6: 635.

11. Sakai, T., and J. Gross. 1967. Some properties of the products of reaction of tadpole collagenase with collagen. Biochemistry. 6: 518.

12. Drake, M. P., P. F. Davison, S. Bump, and F. O. Schmitt. 1966. Action of proteolytic enzymes on tropocollagen and insoluble collagen. Biochemistry. 5: 301.

13. Davison, P. F., and F. O. Schmitt. 1968. The enzymatic dissection of tropocollagen. Hoppe-Seyler's Z. Physiol. Chem. 349: 119.

14. Blumenfeld, O. O., M. A. Paz, P. M. Gallop, and S. Seifter. 1963. The nature, quantity and mode of attachment of hexoses in ichthyocol. J. Biol. Chem. 238: 3835.

15. Spiro, R. G. 1969. Characterization and quantitative determination of the hydroxylysine-linked carbohydrate units of several collagens. J. Biol. Chem. 244: 602.

16. Burge, R. E., and R. D. Hynes. 1959. The thermal denaturation of collagen in solution and its structural implications. J. Mol. Biol. 1: 155.

17. Paz, M. A., R. W. Lent, B. Faris, C. Franzblau, O. O. Blumenfeld, and P. M. Gallop. 1969. Aldehydes in na- tive and denatured calf skin tropocollagen. Biochem. Biophys. Res. Commun. 34 : 221.

18. Nagai, Y., J. Gross, and K. A. Piez. 1964. Disc electrophoresis of collagen components. Ann. N. Y. Acad. Sci. $121: 494$.

19. Bergman, I., and R. Loxley. 1963. Two improved and simplified methods for the spectrophotometric determination of hydroxyproline. Anal. Chem. 35: 1961.

20. Stark, M., and K. Kühn. 1968. The properties of molecular fragments obtained on treating calfskin collagen with collagenase from clostridium histolyticum. Eur. J. Biochem. 6: 534.

21. Harper, E., and S. Seifter. 1965. Mechanism of action of collagenase. Inhibition by cysteine. Fed. Proc. 24: 359.

22. Glynn, M. F., R. Herren, and J. F. Mustard. 1966. Adherence of latex particles to platelets. Nature (Lond.). 212: 79.

23. Jaffe, R., and D. Deykin. 1972. Platelet aggregation initiated by microfibrillar collagen. Fed. Proc. 31: 241.

24. Spaet, T. H., and M. B. Zucker. 1964. Mechanism of platelet plug formation and the role of adenosine diphosphate. Am. J. Physiol. 206: 1267.

25. Harada, K., and M. B. Zucker. 1971. Simultaneous development of platelet factor 4 activity and release of ${ }^{14}$ C-serotonin. Thromb. Diath. Haemorrh. 25: 41.

26. Born, G. V. P., and M. J. Cross. 1963. The aggregation of blood platelets. J. Physiol. (Lond.). 168: 178.

27. Seifter, S., P. M. Gallop, L. Klein, and E. Meilman. 1959. Studies on collagen. II. Properties of purified collagenase and its inhibition. J. Biol. Chem. 234: 285.

28. Seifter, S., and P. M. Gallop. 1966. The structure proteins. In The Proteins. Hans Neurath, editor. Academic Press, Inc., New York. 4 : 153.

29. Piez, K. A. 1968. Crosslinking of collagen and elastin. Ann. Rev. Biochem. 37: 547.

30. Spiro, R. G., and M. J. Spiro. 1971. Studies on the biosynthesis of the hydroxylysine linked disaccharide unit of basement membranes and collagens. J. Biol. Chem. 246: 4899 . 